\title{
The Use of Transgenic Mosquitoes to Control Vertical Transmission of Arbovirus-related IIInesses
}

\author{
The Rationale for Conducting a Field Trial in the Florida Keys and its Relevance to South Texas
}

Globally, mosquitoes - the World's Deadliest Animal, infect over 700 million and are responsible for the death of over one million people every year (1). It is estimated that mosquito-borne illnesses account for $17 \%$ of the estimated global burden of infectious diseases (2). Deadly arboviral diseases transmitted by mosquitoes include (among others) malaria, dengue, West Nile Virus, yellow fever, Zika fever and chikungunya (3). It is common knowledge that male mosquitoes do not bite but rather feed on nectar from flowers. On the contrary, female mosquitoes bite as they need blood to produce eggs (4). Of the many species of mosquitoes, Aedes aegypti is the primary vector that is responsible for vertical transmission of several arboviral diseases and has been most extensively studied (5). Aedes aegypti mosquitoes live in tropical, subtropical and some temperate climate and since they prefer to feed on people, they are most likely to spread arboviral illnesses (6). The efforts of World Health Organization and the Center for Disease Control and Prevention to prevent and/or control mosquito-borne illness have yielded success, but it remains a serious global challenge. More recently, several approaches to create transgenic mosquitoes with the ultimate objective of preventing and/or controlling mosquito-borne illness have undergone field studies. Infecting Aedes aegypti mosquitoes with different strains of Wolbachia resulted in the reduction of egg laying rates and transmission ability and shorter lifespan (7). Similarly, using genetic technology, a selflimiting strain of Aedes aegypti male mosquitoes (OX513A) when released in the field have shown an $81 \%-95 \%$ suppression of population of this strain as compared to adjacent no-release control field (8).

These encouraging results prompted the issuance of authorization by the U.S. Environmental Protection
Agency for the use of second generation genetically modified Aedes aegypti mosquitoes (OX5034) in Florida and Texas (9). OX5034 has a self-limiting gene that prevents female Aedes aegypti offspring from surviving to adulthood. OX5034 is described as a species-specific female larvicide, or "maleselecting" larvicide, that results in all-male progeny in the absence of tetracycline in the larval diet due to a female specific self-limiting gene. With continued field releases of OX5034 homozygous males, the Aedes aegypti population is expected to progressively decline due to the reduced number of females emerging in the area. Specifically, when OX5034 homozygous males are released into the environment and mate with wild Aedes aegypti females, their offspring inherit a single copy of the self-limiting gene. The self-limiting gene kills only female offspring while hemizygous males survive to pass on the OX5034 self-limiting gene further. As the self-limiting gene is inherited in a Mendelian fashion, half of the offspring resulting from a mating between an OX5034 hemizygous male, and a wild female would not inherit the self-limiting gene but would still inherit OX5034 strain genetics. This results in both male and female mosquitoes with OX5034 strain genetics (10).

Despite public opposition, 750 million OX5034 will be ultimately released in the Florida Keys an area devastated by mosquito-borne illnesses (11). This will be the first-ever use of genetically modified mosquitoes in the United States. As an initial field experiment, in the week of May 03, 2021, an estimated 150,000 genetically modified eggs of Aedes aegypti will hatch in six small areas of Ramrod Key, Cudjoe Key and Vaca Key in Florida Keys (12). Since 2019, over one billion genetically modified mosquitoes have been successfully released in parts of Brazil, Cayman Islands, Panama and India to control Aedes aegypti (13). In all these 
studies, there has been no evidence of any harmful effects on humans, animals and or the environment. Considering the available safety data combined with the observed effectiveness of the genetically modified mosquitoes in reducing the burden of arboviral diseases in the community, the decision by the US Environmental Protection Agency was justified. The implications for the success of the use of genetically modified mosquitoes are self-evident and its use must be seriously contemplated for other parts of the nation including South Texas the weather of which, is not dissimilar to Florida Keys.

\section{References}

1. Caraballo H and King K. Emergency department management of mosquito-borne illness: malaria, dengue, and West Nile virus. Emerg Med Pract. 2014 May;16(5):1-23; quiz 23-4. PMID: 25207355

2. Mosquitoes: World's Deadliest Animal. Barcelona Institute of Global Health. https://www.isglobal.org/en/new//asset_publisher/JZ9fGljXnWpI/content/mosquito-el-animalmas-letal-del-mundo

3. Mosquito-borne diseases. The National Institute for Occupational Safety and Health, Centers for Disease Control and Prevention.

https://www.cdc.gov/niosh/topics/outdoor/mosquitoborne/default.html

4. McBride CS, Baier F, et.al. Evolution of mosquito preference for humans linked to an odorant receptor. Nature. 2014 Nov 13;515(7526):222-7. doi: 10.1038/nature13964.

5. Kamal M, Kenawy MA, et.al. Mapping the global potential distribution of two arboviral vectors Aedes aegypti and Ae. Albopictus under changing climate. PLoS One. 2018 Dec 31;13(12):e0210122. doi: 10.1371/journal.pone.0210122. eCollection 2018.

6. Harrington LC, Edman JD and Scott TW. 2001. Why do female Aedes aegypti (Diptera:Culicidae) feed preferentially and frequently on human blood? Journal of Medical Entomology 38:411-422.

7. Xue L, Fang Z, et al. Comparing the effectiveness of different strains of Wolbachia for controlling chikungunya, dengue fever, and zika. PLoS Negl Trop Dis. 2018 Jul 30;12(7):e0006666. doi:10.1371/journal.pntd.0006666. eCollection 2018 Jul.

8. Carvalho DO, McKerney AR, et. al. Suppression of a Field Population of Aedes aegypti in Brazil by Sustained Release of Transgenic Male Mosquitoes. PLoS Negl Trop Dis. 2015 Jul 2;9(7): e0003864. doi:10.1371/journal.pntd.0003864. eCollection 2015.

9. EPA approves experimental Use permit to test innovative biopesticide toll to better protect public health. May 01, 2020. https://www.epa.gov/pesticides/epa-approves-experimentaluse-permit-test-innovative-biopesticide-tool-better-protect.

10. Significant technology advancements set stage for targeted, multi-generation suppression of disease-transmitting mosquitoes. https://www.oxitec.com/en/news/oxitec-launchesfield-trial-in-brazil-for-next-generation-addition-to-friendlymosquitoes-platform

11. Millions of genetically-modified mosquitoes will be deployed to save Floridians from bites.

https://www.zmescience.com/science/genetically-modifiedmosqito-262345/

12. First-ever US release of genetically modified mosquitoes begins in Florida Keys. April 30, 2021.

https://www.cnn.com/2021/04/30/health/genetically-modifiedmosquitoes-us-scn-wellness/index.html

13. de Andrade PP, Aragao FJL, et. al. Use of transgenic Aedes aegypti in Brazil. Risk, perception and assessment. Bull World Health Organ 2016 Oct 1;94(10):766-771. doi:10.2471/BLT.16.173377. Epub 2016 Aug 31.

Sohail Rao, MD, MA, DPhil

Executive Vice President, DHR Health, 5501 S. McColl Road, Edinburg, Texas

President \& Chief Executive Officer, DHR Health Institute for Research \& Development, $5323 \mathrm{~S}$. McColl Road, Edinburg, Texas

Corresponding author email: s.rao@dhr-rgv.com

Disclosures: None

ORCID: Sohail Rao: https://orcid.org/0000-0001-50279992 